\title{
A Multidimensional Review of Bilingual Aphasia as a Language Disorder
}

\author{
Mohsen Akbari (Corresponding author) \\ English Language Teaching Department, Faculty of Humanities, \\ Tarbiat Modares University, Chamran Ave. Tehran, Iran \\ E-mail: mohsena719@yahoo.com
}

Doi:10.7575/aiac.alls.v.5n.2p.73

URL: http://dx.doi.org/10.7575/aiac.alls.v.5n.2p.73
Received: 04/02/2014

Accepted: 28/03/2014

\begin{abstract}
Aphasia as a multifaceted language disorder associated with the complicated links between language and brain has been and is of interest and significance to the stream of research in different disciplines including neurolinguistics, psycholinguistics, cognitive studies and language acquisition. Along with explorations into the manifestations of aphasia in monolingual speakers, bilingual aphasia has similarly become the most current form of this language disorder due to the rising number of bilingual speakers in recent decades all over the world and the probability of facing bilinguals suffering from this language deficit. To paint a picture of this multidimensional linguistic impairment and to get out of the labyrinth of aphasia and in particular bilingual aphasia, the present review study aims to provide a summary of aphasia-related studies in different contexts worldwide and run through the variables affecting the manifestations and language recovery patterns in bilingual aphasic speakers.
\end{abstract}

Keywords: Aphasia, Review, Bilingual, Recovery Patterns, Variables

\section{Introduction}

One of the areas of study on the relationship between language and brain is investigation of language impairment due to brain damage. Aphasia as one of the subparts of the field of language impairment has been and is of significance to the lines of research in linguistics, psycholinguistics, neurolinguistics, and language acquisition. Abundant studies and investigations have been conducted up until now on aphasia-related language deficits (see e.g. Berndt Haendiges, 2000; Goral, 2001; Kljajevic, 2004; Graham and Rochon, 2007; Yarbay Duman, Aygen and Bastiaanse, 2008; Kiran, Sandberg, Gray, Ascenso, and Kester, 2013).

Until recently most research on aphasia has aimed to understand the effects of aphasia on the representation and use of a single language. However, a substantial proportion of the human population speaks more than one language. The number of individuals suffering from acquired language impairments particularly aphasia is striking, and due to the increasing number of bilinguals in the world population, bilingual aphasia is increasingly becoming a very frequent form of aphasia. Therefore, in addition to investigations on manifestations of aphasia in different languages, the study of bilingual aphasia has been of interest to researchers of aphasia and a considerable amount of work has been carried out during the past few decades (e.g. Nilipour and Paradis, 1995; Mendez, 2000; Fabbro and Frau, 2001; Munoz and Marquardt, 2003; Gil and Goral, 2004; Alexiadou and Stavrakaki, 2006; Kambanaros, 2008; Ghafar Samar and Akbari, 2012; Amberber, 2012; Kambanaros and Weekes, 2013).

Such studies can provide a unique opportunity to study the effect of brain damage on different linguistic systems in two languages simultaneously and additionally may allow us to investigate mostly affected aspects of the linguistic system of languages in a bilingual speaker (Alexiadou and Stavrakaki, 2006). As well, according to Fabbro (2001, p. 204), "the study of bilingual aphasics allows us to describe dissociations and double dissociations between the different subcomponents of the various languages". However, in bilingual aphasia there are two main concerns including investigation of aphasia in more than one language and an indispensable problem to tackle that is how languages are affected. One of the most striking features observed in bilinguals who have sustained injury in the language area is the possibility of facing various aphasia-related impairments. In other words, bilinguals do not lose their native and second languages to the same degree after stroke (Giussani, Roux, Lubrano, Gaini and Bello, 2007). Several studies have tried to interpret the different language impairment patterns observed or in Paradis' (1977) words "recovery patterns" in bilingual or multilingual aphasics. The main issues at stake are the reasons why language recovery patterns differ so much across aphasic speakers and why a language recovers better than the other. Therefore, there is a dire need to probe into this issue further to fill some gaps in the literature of aphasia and bilingual aphasia.

Apart from studying bilingual aphasia and its recovery patterns, another concern is to elaborate the variables affecting the manifestations and the recovery pattern of languages. In other words, though the questions concerning the probable manifestations of aphasia in a language or two or more languages in monolingual and bilingual aphasic speakers respectively, and how the two languages are affected in bilingual aphasia have been tackled by pointing to the "recovery patterns" (Paradis, 1977), up until now the variables influencing languages post-stroke and also the recovery patterns in 
bilingual speakers have not been deeply considered in aphasia-related studies. Only few researchers (e.g. Paradis, 2000; Marrero, Golden and Espe-Pfeife, 2002; Gil and Goral, 2004; Lorenzen and Murray, 2008) have mentioned sporadic variables. Therefore, the current review aims to provide a summary of aphasia-related studies in literature and paint a picture of the variables affecting the manifestations and the recovery patterns in bilingual aphasic speakers.

\subsection{Definition of Aphasia}

Aphasia is one of the earliest documented neurological or according to Elkin (2005) "neurophysiological disorders" and has played a central role in advancing the knowledge of brain function. As an acquired language disorder, aphasia is the loss of the ability to produce and/or comprehend language that arises as a consequence of a focal damage to the parts of the brain areas, in particular in the left cerebral hemisphere, which are the main sources for these functions (Vasic, 2006). Its most frequent cause is a cerebral vascular accident (CVA), more commonly known as a stroke (a stroke occurs when blood flow to the brain is interrupted by a clogged or burst artery). The interruption deprives the brain of blood and oxygen, by this means causing brain cells to die. The specific abilities that will be lost or affected by stroke depend on the extent of brain damage and, most importantly, where in the brain the stroke occurred. When brain cells die, functions may become impaired or lost, causing paralysis, speech and language problems, memory and reasoning deficits, coma, and possibly death (Vasic, 2006). Besides, aphasia can also develop as a consequence of an existence or a removal of a brain tumor or as the result of a traumatic brain injury.

Aphasia causes language and communication disorders, particularly problems with each or all language skills and modalities including speaking, listening, reading, and writing. Stated in better words by Koch (2005, p.1); "aphasia is a multimodality deficit that may impair an individual to communicate." In other words, as Vasic (2006) and Rumiati (2007) highlight, aphasia as an acquired language disorder causes deficits of production and comprehension or better to say input and output of verbal messages in individuals with a normal language acquisition history. As they note, in aphasia, spoken and written language as well as reading and auditory comprehension can potentially be impaired. Aphasia can involve the whole linguistic system or it might impair "components or modalities of language" (Rumiati, 2007) or "all linguistic levels" (Vasic, 2006) including phonology, lexicon, morphology, syntax and semantics.

Beside the definitions provided, cited in Shaw (2007), documentation of impaired speech and language following brain impairment dates back to centuries ago. But by the early nineteenth century, discoveries of the relationship between brain and speech-language advanced the perspectives of the disorder that researchers termed as aphasia. The greatest contributions to the study of impaired language and speech were made by Paul Broca and Carl Wernicke (Benton and Anderson, 1998). Broca found the source of impaired language output in his studies and classified it as aphemia that was later termed in his honor as Broca's aphasia. He also postulated the left hemisphere of the brain as the dominant part for language. Following the progress in the field of brain and language studies, Broca's views of brain localization and function were strengthened by the discoveries of Carl Wernicke. In his studies, Wernicke found the main source of impaired language comprehension and classified the language condition as sensory aphasia, now known as Wernicke's aphasia (Benton and Anderson, 1998).

Therefore, from that time on the findings of Broca and Wernicke provided pivotal information about the brain-language relations. Additionally, their findings provided the early classification of aphasia "the classical language areas" (broadly, Broca's and Wernicke's areas) (Paradis, 2009, p.172) and as starting points encouraged others to conduct complementary studies and research. Following their studies there have been many investigations in this field till now.

Counting the general definition of aphasia mentioned above and the early classification of this term made by Broca and Wernicke, aphasia is suggestive of a tree with many branches. In all, aphasia is classified into subparts.

\subsubsection{Classifications of Aphasia}

There are several different systems for categorizing aphasia. These categories originate from different perspectives towards aphasia (see e.g. Thompson's model (2005) with sensory and motor aphasia; Shaw's model (2007) with expressive and receptive aphasia. Although these perspectives encompass nearly all types of aphasia, they are puzzling and unorganized to be used by researchers and scholars.

Therefore, to summarize different perspectives by different scholars, it is better to refer to the more common and comprehensive perspective to the classification of aphasia, in which all types of aphasia are classified into two categories labeled fluent aphasia and non-fluent aphasia. These two terms have been used by several researchers and scholars (e.g. Davis, 1983; Marshall, Lazar and Mohr, 1998; Obler and Gjerlow, 1999; Owens, Metz and Hass, 2000; Fromkin, Rodman and Hyams, 2003; Van der Meulen, 2004; Elkin, 2005; Rumiati, 2007; Shaw, 2007), but the subparts and names employed by some scholars are not clear-cut and comprehensive. Therefore, to shed light on the most common classification of aphasia entitled as fluent and non-fluent aphasia classification, the following summary was provided.

Fluent aphasia or receptive aphasia (Davis, 1983, p.20; Marshall et al., 1998; Owens et al., 2000, p.220; Rumiati, 2007; Shaw, 2007, p.20) and sometimes called sensory aphasia (Davis, 1983, p.20; Marshall et al., 1998; Rumiati, 2007; Shaw, 2007, p.21) is related to the input or reception of language, following difficulties in comprehension of language (Marshall et al., 1998; Obler and Gjerlow, 1999, pp.41-42; Owens et al., 2000, p.220; Elkin, 2005, p.15; Rumiati, 2007; Shaw, 2007, p.23). It typically includes nearly effortless language output and utterances. Examples of fluent aphasia are Wernicke's Aphasia, Transcortical Sensory Aphasia, Conduction Aphasia, and Anomic Aphasia (Davis, 1983, p.20; Marshall et al., 1998; Elkin, 2005, p.15; Rumiati, 2007; Shaw, 2007, p.26). In sum, in fluent aphasia, there is a normal rate of speech without hesitations or pauses but difficulty comprehending speech (Marshall et al., 1998; Elkin, 2005, 
p.15; Rumiati, 2007).

Wernicke's Aphasia as a subpart of fluent aphasia is characterized by abundant amount of fluent and effortless speech (Davis, 1983, p.20; Marshall et al., 1998; Obler and Gjerlow, 1999, pp.42-43; Owens et al., 2000, p.220; Rumiati, 2007); and complex and long syntactic structures with a normal rate, articulation, and intonation (Davis, 1983, p.20; Rumiati, 2007). However, the speech of Wernicke patients is often semantically meaningless and full of paraphasias (word and phoneme substitutions and omissions), neologisms (new words or new meanings for words), non-words, hesitations, circumlocutions and problems in word-finding and repetition (Davis, 1983, p.21; Owens et al., 2000, p.220; Rumiati, 2007). Wernicke's Aphasia as the impaired comprehension of spoken word meaning is also referred to as paragrammatism that involves the unsystematic omission or substitution of morphological affixes that alter the meaning of an utterance often to the point of incoherence (Marshall et al., 1998; Rumiati, 2007). Another subpart of fluent aphasia is Transcortical Sensory Aphasia which includes fluent speech with impaired comprehension (Davis, 1983, p.21; Owens et al., 2000, p.223; Rumiati, 2007). It also is characterized by naming problems, paragrammatism and jargon aphasia (Davis, 1983, p.21; Owens et al., 2000, p.223; Rumiati, 2007). Conduction Aphasia as another example of fluent aphasia is characterized by intact fluency, poor oral and written naming, impaired repetition and comprehension, frequent hesitations, word-finding pauses, and paragrammatism (Davis, 1983, p.21; Marshall et al., 1998; Obler and Gjerlow, 1999, p.43; Owens et al., 2000, p.222; Elkin, 2005, p.15; Rumiati, 2007). And finally Anomic Aphasia includes comprehension, naming and repetition deficits and most importantly trouble in finding the words to express an idea which looks like having a word on the tip of the tongue (Davis, 1983, p.21; Obler and Gjerlow, 1999, p.44; Fromkin et al., 2003, p. 48; Rumiati, 2007).

The second category among the scholars regarding aphasia is non-fluent or expressive aphasia (Davis, 1983, p.20; Marshall et al., 1998; Obler and Gjerlow, 1999, p.39; Owens et al., 2000, p.223; Van der Meulen, 2004, p.5; Rumiati, 2007; Shaw, 2007, p.25) which is related to difficulties in production not comprehension, and it is characterized by effortful output and utterances. Examples of this category of aphasia are Broca's Aphasia, Transcortical Motor Aphasia, and Global Aphasia (Marshall et al., 1998; Owens et al., 2000, p.223; Rumiati, 2007). In sum, in non-fluent aphasia, there is usually effortful, telegraphic production marked by pauses but not impressive difficulty in understanding.

Broca's Aphasia or Motor Aphasia (Davis, 1983, p.20; Marshall et al., 1998; Fromkin et al., 2003, p.45; Van der Meulen, 2004, p.6; Rumiati, 2007; Shaw, 2007, p.23) is characterized by its slow, effortful and hesitating speech, and relatively intact comprehension (Owens et al., 2000, p.223; Fromkin et al., 2003, p.46; Van der Meulen, 2004, p.6; Shaw, 2007, p.22). The speech of Broca patients mainly contains content words. Function words or morphemes as well as syntactic structures are absent (Fromkin et al., 2003, p.45). The speech of these patients has therefore been named telegraphic or agrammatic (Davis, 1983, p.20; Fromkin et al., 2003, p.45; Rumiati, 2007; Shaw, 2007, p.23). There is also impairment and disorder in oral and written expressions and skills, written and oral naming, length of utterances, and fluency. Using single words, short, simplified and fragmented phrases, wrong grammatical order, jargons, wordswitching, intonation-free speech, naming and repetition deficits are among other characteristics of Broca's Aphasia (Davis, 1983, p.20; Marshall et al., 1998; Fromkin et al., 2003, p.46; Van der Meulen, 2004, p.6; Rumiati, 2007). Transcortical Motor Aphasia as another subpart of non-fluent aphasia is characterized by limited spontaneous speech, good comprehension skills, mild auditory comprehension deficits, stuttering, and agrammatism (Davis, 1983, p.20; Owens et al., 2000, p.224; Rumiati, 2007). And after all, Global Aphasia or mixed or total aphasia (Owens et al., 2000, p.224), which is the most sever type of aphasia, includes agrammatism (which includes impairment in grammar and generally lack of ability to construct sentences due to poorly sequenced words or omission of words and inflectional markers), naming, comprehension and repetition deficits, and in all a generalized disruption of all aspects of speech and language (Davis, 1983, p.20; Van der Meulen, 2004, p.6; Rumiati, 2007).

As a whole, aphasia, its classifications and their characteristics are summarized in the Table 1.

Table 1. Aphasia, its classifications and their characteristics in summary

\begin{tabular}{|c|c|}
\hline Fluent aphasia & Non-fluent aphasia \\
\hline a. Wernicke's aphasia & a. Broca's aphasia \\
\hline $\begin{array}{l}\text { 1. Fluent and effortless speech (Owens et al., } \\
2000, p .220\end{array}$ & $\begin{array}{l}\text { 1. Slow, effortful and hesitating speech } \\
\text { (Owens et al., 2000, p.223) }\end{array}$ \\
\hline $\begin{array}{l}\text { 2. Complex and long syntactic structures (Davis, } \\
1983, p .20 \text { ) }\end{array}$ & $\begin{array}{l}\text { 2. Intact comprehension (Fromkin et al., } \\
2003, \text { p.46) }\end{array}$ \\
\hline $\begin{array}{l}\text { 3. Semantically meaningless speech (Rumiati, } \\
\text { 2007) }\end{array}$ & $\begin{array}{l}\text { 3. Absent syntactic structures (Fromkin et } \\
\text { al., 2003, p.45) }\end{array}$ \\
\hline 4. Paraphasia (Davis, 1983, p.21) & Teleoranhic or agrammatic \\
\hline 5. Neologism (Owens et al., 2000, p.220) & (Davis, 1983, p.20) \\
\hline 6. Circumlocution (Davis, 1983, p.21) & Impaired oral and \\
\hline 7. Impaired comprehension (Rumiati, 2007) & (Marshall et al., 1998) \\
\hline 8. Paragrammatism (Rumiati, 2007) & 6. Impaired naming (Davis, 1983, p.21) \\
\hline
\end{tabular}


b. Transcortical sensory aphasia

1. Fluent speech (Owens et al., 2000, p.223)

2. Impaired comprehension (Rumiati, 2007)

3. Naming problems (Davis, 1983, p.21)

4. Paragrammatism (Rumiati, 2007)

5. Jargon aphasia (Owens et al., 2000, p.223)

c. Conduction aphasia

1. Intact fluency (Davis, 1983, p.21)

2. Impaired comprehension (Rumiati, 2007)

3. Poor oral and written naming (Marshall et al., 1998)

4. Frequent hesitations (Obler and Gjerlow, 1999, p.43)

5. Paragrammatism (Rumiati, 2007)

6. Word-finding pauses (Elkin, 2005, p.15)

d. Anomic aphasia

1. Impaired comprehension (Rumiati, 2007)

2. Severe word-finding deficits (Fromkin et al., 2003, p. 48)

3. Repetition deficits (Obler and Gjerlow, 1999, p.44)

4. Impaired naming (Davis, 1983, p.21) b. Transcortical motor aphasia

1. Limited spontaneous speech (Davis, 1983, p.20)

2. Good comprehension skills (Owens et al., 2000, p.224)

3. Mild auditory comprehension deficits (Owens et al., 2000, p.224)

4. Stuttering (Rumiati, 2007)

5. Agrammatism (Rumiati, 2007)

c. Global aphasia

1. Agrammatism (Rumiati, 2007)

2. Impaired naming (Davis, 1983, p.21)

3. Comprehension deficits (Van der Meulen, 2004, p.6)

4. Severe and general disruption of language skills (Davis, 1983, p.20)

At this point, to complete the background of the study together with the general definition and classification of aphasia clarified above, it is a good idea to review the aphasia-related studies, too.

\section{Studies on Aphasia}

The discoveries of Broca and Wernicke offered fundamental information about the brain-language relations and in the function of starting points pushed many researchers in the world to carry out corresponding studies and researches on aphasia in different languages. The following review is a summary of the main characteristics of the aphasia-related studies, case and group studies, in various languages across the world. The framework of the review here is not based on a specific organization; instead the aphasia-related studies are presented based on the languages in which the studies were done. A list of selected publishes studies on the manifestations of aphasia is illustrated in Table 2.

Table 2. A review of selected published studies on manifestations of aphasia in different languages

\begin{tabular}{|c|c|c|c|c|c|}
\hline Authors & Year & Type of study & Purpose of Study & Language & $\begin{array}{l}\text { Language } \\
\text { Assessment } \\
\text { Instrument }\end{array}$ \\
\hline Garraffa and Grillo & 2004 & Group study & $\begin{array}{l}\text { General } \\
\text { manifestations }\end{array}$ & Italian & $\begin{array}{l}\text { Aachen Aphasia } \\
\text { Test (AAT) } \\
\text { (Luzzatti, Willmes } \\
\text { and De Bleser, } \\
\text { 1996) }\end{array}$ \\
\hline $\begin{array}{l}\text { Tsapkini, Jarema and } \\
\text { Kehayia }\end{array}$ & 2001 & Case study & $\begin{array}{l}\text { Morphological } \\
\text { manifestations }\end{array}$ & Greek & $\begin{array}{l}\text { Bilingual Aphasia } \\
\text { Test (BAT) battery } \\
\text { (Paradis, 1987) }\end{array}$ \\
\hline $\begin{array}{l}\text { Bastiaanse, Koekkoek } \\
\text { and Van Zonneveld }\end{array}$ & 2003 & Group study & $\begin{array}{l}\text { Syntactic and } \\
\text { pragmatic } \\
\text { impairments }\end{array}$ & Dutch & $\begin{array}{l}\text { AAT (Graetz, de } \\
\text { Bleser and } \\
\text { Willmes, 1992) }\end{array}$ \\
\hline Blanken, Dittmann and & 2002 & Case study & Production & German & Spontaneous \\
\hline
\end{tabular}




\begin{tabular}{|c|c|c|c|c|c|}
\hline ALLS 5(2):73-86, 2014 & & & & & \\
\hline Wallesch & & & performance & & speech \\
\hline $\begin{array}{l}\text { Bird, Franklin and } \\
\text { Howard }\end{array}$ & 2002 & Group study & $\begin{array}{l}\text { Production and } \\
\text { comprehension }\end{array}$ & English & $\begin{array}{l}\text { Spontaneous } \\
\text { speech }\end{array}$ \\
\hline Laka and Korostola & 2001 & Group study & $\begin{array}{l}\text { Morphological } \\
\text { deficits }\end{array}$ & Basque & $\begin{array}{l}\text { Spontaneous } \\
\text { speech and } \\
\text { interview }\end{array}$ \\
\hline Mansson and Ahlsen & 2001 & Case study & $\begin{array}{l}\text { Grammatical } \\
\text { deficits }\end{array}$ & Swedish & $\begin{array}{l}\text { Conversations and } \\
\text { narratives }\end{array}$ \\
\hline $\begin{array}{l}\text { Leek, Wyn and } \\
\text { Tainturier }\end{array}$ & 2003 & Case study & $\begin{array}{l}\text { Lexical } \\
\text { processing } \\
\text { deficits }\end{array}$ & Welsh & Tasks \\
\hline $\begin{array}{l}\text { Pena-Casanova, } \\
\text { Dieguez-Vide, Lluent } \\
\text { and Bohm }\end{array}$ & 2001 & Case study & $\begin{array}{l}\text { General } \\
\text { manifestations }\end{array}$ & Catalan & Tasks \\
\hline $\begin{array}{l}\text { Semenza, Girelli, } \\
\text { Spacal, Kobal and } \\
\text { Mesec }\end{array}$ & 2002 & Group study & $\begin{array}{l}\text { Language skills } \\
\text { deficits }\end{array}$ & Slovenian & Tasks \\
\hline Ulatowska and Olness & 2001 & Case study & $\begin{array}{l}\text { General } \\
\text { manifestations }\end{array}$ & $\begin{array}{l}\text { African } \\
\text { American } \\
\text { Vernacular } \\
\text { English }\end{array}$ & Interviews \\
\hline $\begin{array}{l}\text { Kertesz and Osman- } \\
\text { Sagi }\end{array}$ & 2001 & Group study & $\begin{array}{l}\text { Agrammatism in } \\
\text { language output } \\
\text { and } \\
\text { comprehension }\end{array}$ & Hungarian & Tasks \\
\hline $\begin{array}{l}\text { Ulatowska, Sadowska } \\
\text { and Kodzielawa }\end{array}$ & 2001 & Case study & $\begin{array}{l}\text { Grammatical } \\
\text { disturbances }\end{array}$ & Polish & BAT \\
\hline Postman & 2003 & Case study & $\begin{array}{l}\text { General } \\
\text { manifestations }\end{array}$ & Indonesian & tasks \\
\hline $\begin{array}{l}\text { Yarbay Duman, Aygen } \\
\text { and Bastiaanse }\end{array}$ & 2008 & Group study & Agrammatism & Turkish & $\begin{array}{l}\text { Gulhane Aphasia } \\
\text { Test (Tanridag, } \\
\text { 1993) }\end{array}$ \\
\hline Nikolova and Jarema & 2004 & Case study & $\begin{array}{l}\text { General } \\
\text { manifestations }\end{array}$ & Bulgarian & Tasks \\
\hline $\begin{array}{l}\text { Bhatnagar, Jain, Bihari, } \\
\text { Bansal, Pauranik, Jain, } \\
\text { Bhatnagar, } \\
\text { Meheshwari, Gupta } \\
\text { and Padma, }\end{array}$ & 2001 & Group study & $\begin{array}{l}\text { General } \\
\text { manifestations }\end{array}$ & Hindi & Tasks \\
\hline Liang and Van Heuven & 2003 & Case study & $\begin{array}{l}\text { General } \\
\text { manifestations }\end{array}$ & Chinese & $\begin{array}{l}\text { Spontaneous } \\
\text { speech }\end{array}$ \\
\hline Salehnejad & 2006 & Case study & Agrammatism & Persian & Task \\
\hline $\begin{array}{l}\text { Kojima, Mimura, } \\
\text { Auchi, Yoshino and } \\
\text { Kato }\end{array}$ & 2011 & Case study & $\begin{array}{l}\text { Linguistic } \\
\text { functions }\end{array}$ & Japanese & Language tests \\
\hline $\begin{array}{l}\text { Bartha, Marien, Poewe } \\
\text { and Benke }\end{array}$ & 2004 & Case study & Linguistic deficits & Belgian & Tasks \\
\hline
\end{tabular}

According to the summary of the findings and conclusions of pertinent studies on aphasia in different languages, the common characteristics of the studies mentioned can be as follows:

- The aphasia-related studies in the world languages can be divided into two parts, case studies and group studies. Selecting the design of aphasia studies depends on several variables including the number of participants available, the types of aphasia at hand, the purpose or purposes of the study, and so forth.

- Using standardized language assessment tests is a prerequisite feature of the studies on aphasia. It was concluded that administering standardized tests for language assessment and diagnosis of the exact type of aphasia is the vital part of each mainstream study. In the studies reviewed several standardized language assessment test were employed and administered. As examples, using Aachen Aphasia Test (Luzzatti et al., 1996); Paradis' (1987) Bilingual Aphasia Test; and Western Aphasia Battery (Kertesz, 1982).

- In addition to using standardized tests for language assessment, it might be a good idea to administer supplementary tasks for further exploration of specific deficits, too, provided that there are not enough tasks in 
the standardized language assessment tests implemented. The supplementary tasks may consist of various tasks depending on the aim of a study, e.g. reading tasks, picture naming tasks, sentence elicitation tasks, oral naming tasks, repetition tasks, as well story-telling, conversations, spontaneous speech, interviews and so on.

- According to many studies reviewed, due to the complicated nature of aphasia it is not possible to reflect on all language modalities and skills in detail in a study. These conditions become stricter when there are aphasic individuals in a group study. Therefore, based on the above-mentioned studies, investigation of aphasia is possible in two ways. First, using a standardized language assessment test to evaluate the overall language abilities of an aphasic person or a group of aphasic individuals; secondly, considering one aspect of language or one modality in detail. As a whole, the main concerns of most studies were to present the manifestations of aphasia in general in all linguistic aspects or in specific ones depending on the aim of study and its scope.

- In many studies reviewed earlier, especially group studies, it was not clear why aphasic individuals showed different performances. Only a few aphasia-related studies had a glance at this issue. For example, Mondini, Jarema and Liguori (2005) raised several possible explanations for the different performances of the subjects and concluded that the participant's performance was influenced by the age of acquisition and the amount of familiarity with Italian, individual differences (mentioned in other studies, e.g. Kljajevic, 2004), gender specific variables, and language-specific features. The effect of language-specific features on aphasic individuals' performance has been mentioned in some other studies (e.g. Penn et al., 2001; Ardila, 2001; Basstianse and Van Zonneveld, 2005); Tsapkini et al. (2001) pointed to taking the particularities of a given language into account when interpreting aphasic manifestations; and finally Bastiaanse and Van Zonneveld (2005) considered the effect of the structure of language on the variety of aphasics' performances.

In general, the numerous studies conducted in the field of aphasia reveal the importance of this complicated form of language impairment. Existing literature of the mainstream studies on aphasia shows that there is no balance in the aphasia-related studies in different languages, i.e. not all languages have enjoyed the developments of investigations regarding the representation and manifestations of aphasia including Japanese, Chinese, Portuguese, Korean, French, Arabic, Urdu, Kurdish, and Persian and so on.

\subsection{Bilingual Aphasia Studies}

As Paradis (2001a) mentions, it is important to become more aware of the manifestations of bilingual aphasia in different contexts due to the probability of facing with people who suffer from aphasia and know more than one language. Accordingly, bilingual aphasia studies reviewed can be classified into four groups based on their findings and results.

The first group of bilingual aphasia studies are those wherein the parallel impairment of both languages in the performance of a bilingual aphasic individual or a group of bilingual aphasics are reported. There are numerous investigations in this respect. For example, Roberts and Deslauriers' (1999) study on a group of French-English bilingual aphasics assessed by the Boston Diagnostic Aphasia Examination (BDAE) (Goodglass and Kaplan, 1982); Lim, Douglas and Lambier's study (1999) on the production abilities of a group of bilingual Mandarin-Chinese speakers with aphasia through several tasks; a study on the performance of a group of bilingual Friulian-Italian aphasic participants by Fabbro and Frau (2001) implementing the two versions of the BAT in Friulian and Italian for language assessment; an investigation by Croft, Marshall and Pring (2006) on Bengali-English bilingual aphasic speakers focusing on the participants' word finding difficulties; a study (Kambanaros, 2007) on bilingual Greek-English fluent aphasics with more focus on spontaneous speech; and a study (Jarema, Perlak and Semenza, 2007) on two EnglishFrench aphasic individuals focusing on processing of compounds; an investigation on a case of a French-Dutch bilingual patient via tasks (Verreyt, De letter, Hemelsoet, Stantens and Duyck, 2013).

As the second group of studies conducted in the field of bilingual aphasia, there are several investigations in which the second language (L2) of the bilingual aphasics is reported to be more impaired than the first language (L1). As examples; a group study (Nilipour and Paradis, 1995) on grammatical deficits of Persian-English bilingual aphasics via BAT; a case study (Mendez, 2000) on a bilingual Spanish-English aphasic person; Weekes, Su, Yin and Zhang's study (2007) on Mongolian-Chinese bilingual aphasia; a multiple case study (Poncelet, Majerus, Raman, Warginaire and Weeks, 2007) on the errors made by three bilingual aphasic, a Turkish-English speaker and two German-French speakers; an investigation on the performance of a bilingual Spanish-Catalan case (Hernandez, Cano, Costa, SebastianGalles, Juncadella and Gascon-Bayarri, 2008); Amberber's study (2012) on a French-English bilingual aphasic speaker via BAT.

The third group of studies in the field of bilingual aphasia are those in which the impairment of both languages in a bilingual aphasic or a group of bilingual aphasics is reported to be unclear i.e. both languages were impaired in selective aspects. As examples, Munoz and Marquardt's (2003) investigation on the performance of four bilingual speakers of Spanish and English with aphasia; a study (Almagro, Sanchez-Casas and Garcia-Albea, 2003) on the production and comprehension of a Catalan-Spanish bilingual patient; Gil and Goral's investigation (2004) on bilingual aphasia in a Russian-Hebrew aphasic speaker; a study on an English-Dutch bilingual aphasic (Marien, Abutalebi, Engelborghs and De Deyn, 2005); Alexiadou and Stavrakaki's (2006) study on the performance of a Greek-English bilingual patient with Broca's aphasia and mild agrammatism using production and comprehension tasks; case study (Meinzer, Obleser, Flaisch, Eulitz, and Rockstroh, 2007) on the performance of a bilingual patient (German/French) with chronic aphasia via several tasks; a study on a Galician-Spanish bilingual aphasic (Garcia-Caballero, Garcia-Lado, Gonzalez-Hermida, 
Area, Recimil, and Juncos Rabadan, 2007); a case study (Kambanaros, 2008) on the performance of a Greek-English bilingual aphasic person; Kambanaros andWeekes' investigation (2013) on phonological deficits among Greek-English bilinguals.

Finally, there is a group of bilingual aphasia studies in which the first language (L1) is reported to be more impaired than the second language (L2). As examples, Aglioti, Beltramello, Girardi, and Fabbro's (1996) study on an ItalianEnglish case; Fabbro and Paradis' (1995) report on a Venetian-Italian aphasic case; Scarna and Ellis' (2002) report on the case of a bilingual Italian-English aphasic patient; Filley, Ramsberger, Menn, Wu, Reid and Reid's (2006) study on a Chinese-English bilingual aphasic speaker; Sebastian, Kiran and Sandberg's study (2012) on semantic processing in Spanish-English bilingulas with aphasia; a study on a bilingual Kurdish-Persian case by Ghafar Samar and Akbari (2012). an investigation on Spanish-English bilingual individuals with aphasia (Kiran, Sandberg, Gray, Ascenso and Kester, 2013).

According to the summary of the findings and conclusions of pertinent studies on bilingual aphasia in different contexts, the common characteristics of the studies mentioned can be as follows:

- The bilingual aphasia studies can be classified into two groups, case studies and group studies. Selecting the design of bilingual aphasia studies depends on several variables including the number of participants available, the types of aphasia at hand, the purpose or purposes of the study, the scope of the study, and the like.

- Using standardized language assessment tests is a necessity for the studies on bilingual aphasia. It was concluded that administering standardized equivalent tests for assessment of both languages and diagnosis of the exact type of aphasia is the essential part of each mainstream bilingual aphasia study. In the studies reviewed several standardized language assessment test were employed and administered. As examples, the Boston Diagnostic Aphasia Examination (BDAE) (Goodglass and Kaplan, 1982); and the diverse versions of the Bilingual Aphasia Test (BAT) (Paradis, 1987).

- In addition to using standardized tests for assessment of both languages, it might be a useful idea to administer supplementary tasks for further exploration of specific deficits in both languages, too, provided that there are not suitable and enough tasks in the standardized language assessment test implemented; the different versions of a language assessment test are not at hand in various languages, or the scope of the study is to investigate language deficits in detail. The supplementary tasks may consist of various tasks depending on the aim of a study, e.g. reading tasks, picture naming tasks, sentence elicitation tasks, oral naming tasks, repetition tasks, as well story-telling, conversations, spontaneous speech, interviews and so on. However, there might be several problems including inequality of the tests and their unreliability.

- According to the studies reviewed, due to the intricate nature of aphasia it is not viable to consider all language modalities and skills in detail in a study. These conditions become stringent when there are bilingual aphasic individuals in a group study. Therefore, based on the above-mentioned studies, investigation of bilingual aphasia is possible in two modes. First, using an equivalent and standardized language assessment test to evaluate the overall language ability of a bilingual aphasic person or a group of aphasic individuals; secondly, considering one aspect of language or one modality in detail. As a whole, the main concerns of most bilingual studies were to present the manifestations of aphasia in general in all linguistic aspects or in specific ones depending on the aim of study and its scope.

- According to the studies reviewed, it was concluded that bilingual aphasic speakers do not usually depict similar or different manifestations in both languages; rather there are several language impairment patterns which are elaborated in Paradis' terms (1977) as four "Language Recovery Patterns" among bilingual aphasic speakers. Since the pioneering study of the French neurologist Pitres (1895), who was the first to draw attention to the variety of language recovery patterns following aphasia in bilinguals, many different recovery patterns have been described. The diversity of possible patterns is almost endless; however, some form of classification and description of the most frequently encountered recovery patterns was needed to assure coherence for researchers and clinicians (Ansaldo, et al. 2008). Cited in Green (2005), Paradis, 1977 described six different basic recovery patterns, corresponding to the most frequently observed language profiles of recovery from bilingual aphasia. The first recovery pattern is "parallel recovery" which includes impairment of both languages to a similar extent and concurrently. The next pattern is "differential recovery". This recovery occurs when languages recover differentially relative to their pre-morbid levels. Another pattern wherein after the recovery of one language, the other language recovers is called "successive recovery". Then, when at least one language is not recovered at all "selective recovery" occurs. After that, there is alternating recovery in which the language that was first recovered is lost again due to the recovery of the language that was not first recovered. And finally, the pathological mixing of two languages or "blended recovery" wherein the elements of the two languages are involuntarily mixed during language production and patients mix their languages inappropriately.

- In many studies reviewed earlier, it was not clear why bilingual aphasic individuals showed different performances, though in several studies a few variables were mentioned indirectly (e.g. Aglioti et al. ,1996; Lim et al., 1999; Mendez, 2000; Fabbro and Frau, 2001; Munoz and Marquardt, 2003; Alexiadou and Stavrakaki, 2006; Weekes et al., 2007; Hernandez et al., 2008). 
- According to the above review, there are several variables that probably have influence on the performance of a bilingual aphasic speaker. Due to these variables, each bilingual aphasic speaker might have the same or different performance in each language. As the review of the related literature revealed, these variables have not been in the scope of most studies; however, several studies have considered them in interpretations of results and further discussions. The remarkable variables mentioned in the studies involved the specific features intrinsic to each language (Lim et al.,1999) such as the similar structure of the languages (Fabbro and Frau, 2001), the linguistic properties of each language (Alexiadou and Stavrakaki, 2006; Weekes et al., 2007; Poncelet et al., 2007; Hernandez et al., 2008) ; the pre-morbid degree of familiarity with a language or proficiency (Mendez, 2000 ; Munoz and Marquardt, 2003; Poncelet et al., 2007); the context of learning a language before the stroke (Fabbro and Frau, 2001); the type of aphasic syndrome and the type and site of the lesion (Fabbro and Frau, 2001; Poncelet et al., 2007); the age of language acquisition (Mendez, 2000); and finally the organization of the components of languages in procedural and declarative memory systems (Aglioti and Fabbro, 1993; Fabbro and Paradis ,1995; Aglioti et al., 1996)

- It was also revealed that there is no complete study in bilingual aphasia in which the two sides of the coin are considered. To be exact, there is no study wherein the manifestations of aphasia in a bilingual case or a group of bilingual aphasic speakers have been interpreted with several effective variables in a comprehensive way.

In sum, the studies reviewed revealed that there are four types of language impairment patterns in a bilingual aphasic individual or a group of bilingual aphasics including the same impairment of both languages, impaired L2, differential impairment of both languages, and impaired L1. Theses types of language impairments were labeled in Paradis' terms (1977) as "language recovery patterns" in bilingual aphasics. In addition to the classification of the manifestations of bilingual aphasia into four groups, the main point in numerous studies reviewed above was that most of them only were to answer the question of How the languages in a bilingual aphasic speaker are impaired?

Although the studies revealed four types of language impairment patterns and answered the impairment patterns of languages in a bilingual aphasic or bilingual aphasics, the point neglected in the above-mentioned studies was that no study was to look for and discuss the main variables affecting the patterns of language impairment. It should be mentioned that just several studies highlighted a few variables in interpretations of results and further discussions (see e.g. Aglioti and Fabbro, 1993; Aglioti et al. ,1996; Lim et al., 1999; Mendez, 2000; Fabbro and Frau, 2001; Fabbro, 2001a; Munoz and Marquardt, 2003; Alexiadou and Stavrakaki, 2006; Weekes et al., 2007; Hernandez et al., 2008) and there was not a complete study done in this regard i.e. providing the manifestations of aphasia in a bilingual aphasic speaker or a group of bilingual speakers as well as the influential variables leading to the manifestations.

\section{Variables Affecting Aphasia-related Manifestations and Language Recovery Patterns}

In addition to preparing a review studies on the manifestations of aphasia in monolingual and bilingual speakers in different linguistic contexts, another concern of the study was to seek for the variables affecting the language deficits and language recovery patterns.

While the range of language recovery patterns demonstrated by bilingual patients with neurological damage has been well documented (Paradis, 2001a), the review of related literature, to our information, revealed that no comprehensive study has been done in this regard, there have been sparse studies in which the influential variables on the manifestations of aphasia in monolingual or bilingual aphasia have been presented but not discussed in detail. However, the detailed exploration of these studies and the variables mentioned demonstrated that there are variables or several extraneous variables mentioned in Paradis' words (2001a) as "Critical Variables" which play leading roles in the manifestations and also the recovery pattern of aphasia in a monolingual or bilingual speaker. These variables according to a review of previous studies were summarized as follows.

\subsection{Severity of aphasia}

According to Fabbro (2001a) one of the variables affecting aphasia-related language deficits, different language impairment patterns, and different impairments in bilingual aphasics is the site and extent of lesion to the brain. In another term, "severity of aphasia" (Nilipour, 2000; Paradis, 2001b; Green, 2005) which is the result of a lesion at a given site and extent that may yield different effects on monolingual and bilingual aphasic speakers.

\subsection{Pre-morbid language proficiency}

The second variable that might affect different manifestations of aphasia in a bilingual speaker is language proficiency before the onset of aphasia. This variable has been considered in several studies on bilingual aphasia as a critical variable (Gil and Goral, 2004; Ansaldo et al., 2008; Hernandez et al., 2008). According to Fabbro (2001b), to become aware of the pre-morbid language performance in a language or languages is essential to determine the pattern of aphasic impairments. As Fabbro (2001b) mentions, a patient with more proficiency in L1 before aphasia onset, may still be so after the brain injury. Moreover, pre-morbid proficiency across language modalities can have an impact on the bilingual aphasia pattern, and thus should be considered to avoid misdiagnosis. Implicitly stated in the studies on aphasia or bilingual aphasia, it is concluded that the degree of proficiency (Galloway, 1982) or the level of proficiency (Roberts and Deslauriers, 1999; Lorenzen and Murray, 2008) in a language in an aphasic speaker or in each language in a bilingual speaker pre-onset of aphasia appears to affect language representations. More proficiency in a language before aphasia might be a determining variable for fewer deficits in the performance of a monolingual or bilingual aphasic case. The hypothesis is that the bilingual aphasic individual's L2 was his/her less-proficient language, so there 
would be more deficits in L2 than L1. In other studies, language proficiency has been regarded with other perspectives; for example, familiarity with a language ( Paradis, 2001a; Marrero, Golden and Espe-Pfeifer, 2002; Laiacona, Luzzatti, Zonca, Guarnaschelli and Capitani, 2002; Mondini et al., 2005); the degree of mastery (Perani and Abutalebi, 2005). In conclusion, it should be stated that a language in which the bilingual was literate proficient before the injury stands a better chance of being recovered than a language which he/she could only speak.

\subsection{Age of language acquisition}

In addition to pre-morbid proficiency on a language or languages, age of language acquisition as another important variable affecting the manifestations of aphasia in monolingual and bilingual aphasic speakers has been identified (e.g. Gil and Goral, 2004; Mondini et al., 2005; Ansaldo, Marcotte, Scherer and Raboyeau, 2008; Paradis, 2008). Considering this variable, it is stated that the languages learned at different ages would have differential language deficit patterns. In other words, according to several studies (Roberts and Deslauriers, 1999; Paradis, 2001a; Marrero, Golden and Espe-Pfeifer, 2002; Laiacona et al., 2002; Perani and Abutalebi, 2005; Green, 2005; Hernandez et al., 2008; Lorenzen and Murray, 2008) the age of first or second language acquisition has a direct effect on the manifestations of aphasia especially in bilingual aphasic speakers. It is believed that the age of second language acquisition affects language proficiency and both these variables might affect language performance particularly in bilingual aphasic speakers. As a whole, as Gil and Goral (2004) points out, age is an effective variable which can lead to more or less language impairments and in particular "the first language which is learned at a specific age would be the least affected by brain damage".

\subsection{Context of language acquisition}

The next variable is the context of language acquisition (Marrero, Golden and Espe-Pfeifer, 2002). According to Gil and Goral (2004); "it is hypothesized that languages acquired in the same context are more likely to demonstrate the same language deficits patterns, while languages acquired in different contexts would be more likely to show differential patterns". In Ansaldo et al.'s terms (2008), language exposure and use or language dominance has an effect on the representation of language impairments. This variable has been taken into account using other terms; for instance, "setting of the use of languages" (Galloway, 1982); and "pre-morbid exposure"(Fabbro, 2001b; Perani and Abutalebi, 2005)

\subsection{Individual characteristics of languages}

The characteristics of a language following the structural relations among the two languages particularly bilingual aphasic speakers is another variable proposed for language deficit patterns in a monolingual or bilingual aphasic case (Paradis, 1988; Ardila, 2001; Paradis, 2001a; Marrero, Golden and Espe-Pfeifer, 2002; Alexiadou and Stavrakaki, 2003; Gil and Goral; 2004; Paradis, 2008; Lorenzen and Murray, 2008). Considering this view, it is stated that the underlying structures that are common to all languages would influence each other in their representation of language deficits. Also it is concluded that in the more surface, language-specific structures of each language, there would be less similar deficits (Gil and Goral, 2004; Green, 2005; Mondini et al., 2005; Bastiaanse and Van Zonneveld, 2005). In a recent hypothesis, Paradis (2008) declares that "bilingual aphasia manifestations differ as a function of the structural diversity of their languages". It is stated that language-specific characteristics (Nilipour, 2000; Goral, 2001; Paradis, 2001b; Nilipour and Raghibdoust, 2001; Fabbro, 2001b; Laiacona et al.,2002) or language-related differences might have effects on language representations in aphasic speakers especially bilingual aphasics. So, the particular characteristics of a language or the specific system of a language (Tsapkini, Jarema and Kehayia, 2001) or "the different linguistic properties of L1 and L2" (Nilipour and Paradis, 1997; Paradis, 2001a; Weekes et al., 2007) should be considered as variables affecting aphasia-related representations.

\subsection{Manner of language acquisition}

Together with the above-mentioned variables, another recently noticed variable affecting the manifestations of aphasia and language impairment patterns in monolingual and bilingual aphasic speakers is the manner of language acquisition (Galloway, 1982; Paradis, 2000, 2004, 2008; Gil and Goral, 2004; Ansaldo et al., $\quad 2008$; Hernandez et al., 2008). This variable is related to the organizational principles involved in the representations of languages, here L1 and L2, in the brain. In addition, the manner of language acquisition encompasses the role of declarative and procedural memory or "the declarative/procedural framework" and further "implicit/explicit memory processing" (Paradis, 2000, 2004, 2008). Therefore, it can be stated that memory processing embedded in the manner of language acquisition might have effects on the representations of aphasia and language impairment patterns, too.

Further, as maintained by Paradis $(2000,2004,2008)$, bilinguals rely upon different memory resources. Early bilinguals acquire languages by mere exposure and need not be aware of the rules that govern either of their spoken languages; learning is mainly dependent upon implicit memory processing. Conversely, if the second language is acquired after infancy, specific language components such as phonology, syntax, morphology, and semantics are consciously learnt, and thus declarative memory resources are solicited. As he states, the second language tends to be relying to a greater extent (in acquisition and recovery from aphasia) on meta-linguistic knowledge dependent on declarative memory and learned during the appropriation of the second language; and the first language tends to be dependent on implicit linguistic competence which relies on procedural memory. In sum, implicit competence exists for only one language by procedural memory i.e. the first language and explicit competence depends on declarative memory that is used for second language acquisition. So, it is concluded that the manner of language acquisition might be one of the variables that affects language deficits and language recovery patterns in monolingual and bilingual aphasic speakers. 
As a whole, the influential variables affecting the manifestations of aphasia in monolingual and bilingual aphasic speakers and also the recovery patterns are the severity of aphasia, pre-morbid language proficiency, the age of language learning, the context of language acquisition, the specific structure of a language or the structural relations of languages in a bilingual speaker, and the manner of language acquisition which includes implicit and explicit competence that rely on declarative and procedural memory, respectively.

\section{Conclusion}

The review of related literature was done in order to make clear the meaning of aphasia as an acquired cognitive and communicative disorder (Lorenzen and Murray, 2008), to prepare a review of the studies conducted in the field of aphasia and bilingual aphasia and illustrate the main variables affecting the performance of the patient.

The review revealed that there are different viewpoints to aphasia and its classifications. The outstanding classification was summarized as fluent and non-fluent aphasia. Additionally, the general review of studies on aphasia in different languages in the world showed that there are two groups of studies in this regard including case studies and group studies depending on several variables such as the number of participants available, the types of aphasia at hand, and the purpose or purposes of the study. To do such studies standardized language assessment tests are required, it might be a good idea to administer supplementary tests and tasks, though.

Moreover, based on the above-mentioned studies, investigation of aphasia is possible in two ways. First, using a standardized language assessment test to evaluate the overall language abilities of an aphasic person or a group of aphasic individuals; secondly, considering one aspect of language or one modality in detail.

In aphasia studies reviewed earlier, it was not clear why aphasic individuals showed different performances, a few studies (Tsapkini et al., 2001; Ardila, 2001; Kljajevic, 2004; Mondini et al., 2005; Basstianse and Van Zonneveld, 2005) had a glance at this issue, however.

As a whole, although the aphasia-related studies unveiled the importance of this complicated form of language impairment, the existing literature showed imbalance in the aphasia-related studies in different languages, i.e. not all languages have enjoyed the developments of investigations regarding the representation and manifestations of aphasia.

In addition to review of the investigations on monolingual aphasic speakers, a review of the bilingual aphasia studies in the world languages was done. In these case and group studies, there were more challenges due to facing bilinguals with two impaired languages. Like the language assessment tests for monolingual aphasic speakers, bilingual aphasia also needs two standardized, systematic, and equivalent language assessment tests administered in the same conditions and settings for both languages.

According to the bilingual studies reviewed, it is not viable to consider all language modalities and skills in detail in a study. Therefore, based on the above-mentioned studies, investigation of bilingual aphasia is possible in two modes. First, using an equivalent and standardized language assessment test to evaluate the overall language ability of a bilingual aphasic person or a group of aphasic individuals; secondly, considering one aspect of language or one modality in detail.

Additionally, as the studies reviewed showed, bilingual aphasic speakers do not usually depict similar or different manifestations in both languages; rather there are several language impairment patterns which are elaborated in Paradis' terms (1977) as "Language Recovery Patterns" among bilingual aphasic speakers including parallel, differential, successive, selective, alternating, and blended recovery. In spite of establishing recovery patterns, in many studies reviewed earlier, it was not clear why bilingual aphasic individuals showed different performances, though in several studies a few variables were mentioned indirectly (e.g. Aglioti and Fabbro, 1993; Aglioti et al. ,1996; Lim et al., 1999; Mendez, 2000; Fabbro, 2001a; Fabbro and Frau, 2001; Munoz and Marquardt, 2003; Alexiadou and Stavrakaki, 2006; Weekes et al., 2007; Hernandez et al., 2008).

The remarkable variables mentioned in the studies involved the linguistic properties of each language (Lim et al.,1999; Fabbro and Frau, 2001; Alexiadou and Stavrakaki, 2006; Weekes et al., 2007; Poncelet et al., 2007; Hernandez et al., 2008), the pre-morbid degree of familiarity with a language or proficiency (Mendez, 2000 ; Munoz and Marquardt, 2003; Poncelet et al., 2007), the context of learning a language before the stroke (Fabbro and Frau, 2001), the type of aphasic syndrome and the type and site of the lesion (Fabbro and Frau, 2001; Poncelet et al., 2007), the age of language acquisition (Mendez, 2000), and finally the organization of the components of languages in procedural and declarative memory systems (Aglioti and Fabbro, 1993; Fabbro and Paradis ,1995; Aglioti et al., 1996).

It was also revealed that there is no complete study in bilingual aphasia in which the two sides of the coin are considered. To be exact, there is no study wherein the manifestations of aphasia in a bilingual case or a group of bilingual aphasic speakers have been interpreted with several effective variables in a comprehensive way.

And finally, while the range of language recovery patterns demonstrated by bilingual patients with neurological damage has been well documented (Paradis, 2001a), the review of related literature, to our information, revealed that no comprehensive study has been done in this regard, there have been sparse studies in which the influential variables on the manifestations of aphasia in monolingual or bilingual aphasia have been presented but not discussed in detail. However, the detailed exploration of these studies and the variables mentioned demonstrated that there are variables or several extraneous variables mentioned in Paradis' words (2001a) as "Critical Variables" which play leading roles in the manifestations and also the recovery pattern of aphasia in a monolingual and bilingual aphasic.

In sum, this review focusing on different aspects of aphasia was not fully inclusive of all of the work put forth in this 
domain of research; rather, it addressed only the most related studies. Therefore, more review studies in the fields of aphasia and bilingual aphasia are required to complement the current study.

\section{References}

Aglioti, S., \& Fabbro, F. (1993). Paradoxical selective recovery in a bilingual aphasic following subcortical lesions. NeuroReport, 4, 1359-1362.

Aglioti, S., Beltramello, A., Girardi, F., \& Fabbro, F. (1996). Neurolinguistic and follow-up study of an unusual pattern of recovery from bilingual subcortical aphasia. Brain, 119, 1551-1564.

Alexiadou, A., \& Stavrakaki, S. (2006). Clause structure and verb movement in a Greek-English speaking bilingual patient with Broca's aphasia: Evidence from adverb placement. Brain and Language, 96, 207-220.

Almagro, Y., Sanchez-Casas, R., \& Garcia-Albea, J.E. (2003). A case study of anomia: grammatical category in the production of a bilingual aphasic. Cognitiva, 15(1), 33-49.

Amberber, A. M. (2012). Language intervention in French-English bilingual aphasia: evidence of limited therapy transfer. Journal of Neurolinguistics, 25(6), 588-614.

Ansaldo, A.I., Marcotte, K., Scherer L., \& Raboyeau, G. (2008). Language therapy and bilingual aphasia: clinical implications of psycholinguistic and neuroimaging research. Journal of Neurolinguistics, 21(6), 539-557.

Ardila, A. (2001). The manifestation of aphasic symptoms in Spanish. Journal of Neurolinguistics, 14, $337-347$.

Bartha, L., Marien, P., Poewe, W., \& Benke, T. ( 2004). Linguistic and neuropsychological deficits in crossed conduction aphasia: report of three cases. Brain and Language, 88(1), 83-95.

Bastiaanse , R., Koekkoek, J., \& Van Zonneveld, R. (2003). Object scrambling in Dutch Broca's aphasia. Brain and Language, 86, 287-299.

Bastiaanse , R., \& Van Zonneveld, R. (2005). Sentence production with verbs of alternating transitivity in agrammatic Broca's aphasia. Journal of Neurolinguistics, 18, 57-66.

Benton , A., \& Anderson, S.W. (1998). Aphasia: historical perspectives. In M.T. Sarno (Ed.), Aquired Aphasia (3 ${ }^{\text {rd }}$ ed., pp.1-20). San Diego: Academic Press.

Berndt, R.S., \& Haendiges, A. N. (2000). Grammatical class in word and sentence production: evidence from an aphasic patient. Journal of Memory and Language, 43, 249-273.

Bhatnagar, S.C., Jain, S. K., Bihari, M., Bansal, N. K., Pauranik, A., Jain, D.C., Bhatnagar, M.K., Meheshwari, M.C., Gupta, M., \& Padma, M.V. (2002). Aphasia type and aging in Hindi-speaking stroke patients. Brain and Language, 83, 353-361.

Bird, H., Franklin, S., \& Howard, D. (2002). 'Little words' - not really: function and content words in normal and aphasic speech. Journal of Neurolinguistics, 15, 209-237.

Blanken, G., Dittmann, J., \& Wallesch, C. (2002). Parallel or serial activation of word forms in speech production? Neurolinguistic evidence from an aphasic patient. Neuroscience Letters, 325, 72-74.

Croft, S., Marshall, F., \& Pring, T. (2006). Assessing noun naming impairments in bilingual aphasia. Brain and Language, 99, 8-219.

Davis, G. A. (1983). A survey of adult aphasia. Englewood cliffs, N.J: Prentice-Hall Inc.

Elkin, B. (2005). Neurocognitive rehabilitation of aphasia in bilingual patients: A program design. Unpublished Doctoral Dissertation. Carlos Albizu University: Miami, Florida.

Fabbro, F. (2001). The bilingual brain: cerebral representation of languages. Brain and Language, 79, 211-222.

Fabbro, F., \& Frau, G. (2001).Manifestations of aphasia in Friulian. Journal of Neurolinguistics, 14, 255-279.

Fabbro, F., \& Paradis, M. (1995). Differential impairments in four multilingual patients with subcortical lesions. In M. Paradis (Ed.), Aspects of bilingual aphasia (pp. 139-176). Oxford: Pergamon Press.

Filley, C. M., Ramsberger, G., Menn, L., Wu, J., Reid, B. Y., \& Reid, A. L. (2006). Primary progressive aphasia in a bilingual woman. Neurocase, 12(5), 296-299.

Fromkin, V., Rodman, R., \& Hyams, N. (2003). An introduction to language, ( $7^{\text {th }}$ ed.). Massachusetts: Heinle.

Galloway, L. (1982). The convolutions of second language. Language Learning, 31, 439-464.

Garcia-Caballero, A., Garcia-Lado, I., Gonza lez-Hermida, J., Area, R., Recimil, M. J., \& Juncos Rabadan, O. (2007). Paradoxical recovery in a bilingual patient with aphasia after right capsuloputaminal infarction. Journal of Neurology, Neurosurgery and Psychiatry, 78, 89-91.

Ghafar Samar, R., \& Akbari, M. (2012). A language teacher in the haze of bilingual aphasia: a Kurdish-Persian case. Procedia - Social and Behavioral Sciences, 32, 252-257.

Gil, M., \& Goral, M. (2004). Nonparallel recovery in bilingual aphasia: effects of language choice, language proficiency, and treatment. International Journal of Bilingualism, 8(2), 191-219. 
Giussani, C., Roux, F. E., Lubrano, V., Gaini, S. M., \& Bello, L. (2007). Review of language organization in bilingual patients: what can we learn from direct brain mapping? Acta Neurochirurgica, 149, 1109-1116.

Goodglass, H., \& Kaplan, E. (1982). The assessment of aphasia and related disorders (2nd ed.). Philadelphia: Lea and Febiger.

Goral, M. (2001). Aphasia in Hebrew Speakers. Journal of Neurolinguistics, 14, 297-312.

Graetz, P., de Bleser, R., \& Willmes, K. (1992). Akense Afasietest (AAT). Lisse: Swets and Zeitlinger.

Graham, N.L., \& Rochon, E. (2007). Verb production in sentences by patients with non-fluent progressive aphasia. Brain and Language, 103, 8-249.

Green, D. W. (2005). The neurocognition of recovery patterns in bilingual aphasics. In J. F. Kroll, and A. M. B. de Groot (Eds.), Handbook of bilingualism: Psycholinguistic perspectives (pp. 516-530). New York: Oxford University Press.

Hernandez, M., Cano, A., Costa, A., Sebastian-Galles, N., Juncadella, M., \& Gascon-Bayarri, J. (2008). Grammatical category-specific deficits in bilingual aphasia. Brain and Language, 107(1), 68-80.

Jarema, G., Perlak, D., \& Semenza, C. (2007).The processing of compounds in bilingual aphasia. Brain and Language, 103, 8-249.

Kambanaros, M. (2007). Action naming versus verb retrieval in connected speech: Evidence from late bilingual GreekEnglish fluent anomic aphasic speakers. Brain and Language, 103, 8-249.

Kambanaros, M. (2008).The trouble with nouns and verbs in Greek fluent aphasia. Journal of Communication Disorders, 41, 1-19.

Kambanaros, M., \& Weekes, B. S. (2013). Phonological dysgraphia in bilingual aphasia: evidence from a case study of Greek and English. Aphasiology, 27(1), 59-79.

Keljajevic, V. (2004). Comprehension of Wh-dependencies in Broca's aphasia. Unpublished doctoral dissertation. Carlton University: Ontario.

Kertesz, A. (1982). Western Aphasia Battery. New York: Grune and Stratton.

Kertesz, A. \& Osman-Sagi, J. (2001). Manifestations of aphasic symptoms in Hungarian. Journal of Neurolinguistics, 14, 313-319.

Kiran, S., Sandberg, C., Gray, T., Ascenso, E. \& Kester, E. (2013). Rehabilitation in bilingual aphasia: evidence for within- and between-language generalization. American Journal of Speech and Language Pathology, 22(2), 298-309.

Koch, M. E. (2005). Prediction of strategy usage by adults with aphasia. Unpublished M.S. Thesis. Southern Connecticut State University: New Haven, Connecticut.

Kojima, T., Mimura, M., Auchi, K., Yoshino, F., \& Kato, M. (2011).Long-term recovery from acquired childhood aphasia and changes of cerebral blood flow. Journal of Neurolinguistics, 24(1), 96-112.

Laiacona, M., Luzzatti, C., Zonca,G., Guarnaschelli, C., \& Capitani, E. (2002). Lexical and semantic variables influencing picture naming in aphasia. Brain and Cognition, 46(1), 184-187.

Laka, I., \& Korostola, L. E. (2001). Aphasia manifestations in Basque. Journal of Neurolinguistics, 14, 133-157.

Leek, E.C., Wyn, R., \& Tainturier, M. J. (2003). Syntactic mediation is not obligatory during lexical access: Evidence from a single-case study of Welsh aphasia. Brain and Cognition, 53, 268-272.

Liang, J., \& van Heuven. V. J. (2003). Evidence for separate lexical tone and sentence intonation: a perception study of Chinese aphasic patients. Paper presented at the 4TH Science of Aphasia Conference Trieste, Italy. Retrieved on September $10^{\text {th }}$, 2012 from http://www.soa5.de/pdf/SoA4_prog-abstracts03.pdf

Lim, V., Douglas, J., \& Lambier, J. (1999). Impairment of lexical tone production in stroke patients with bilingual aphasia. Abstracts of the 22nd Annual Brain Impairment Conference, Sydney.

Lorenzen, B., \& Murray, L. L. (2008). Bilingual aphasia: a theoretical and clinical review. American Journal of Speech and Language Pathology, 17(3), 299-318.

Luzzatti, C., Willmes, W., \& De Bleser, R. (1996). Aachener Aphasia Test (AAT): Versione Italiana, 2nd ed. Florence: Organizzazioni Speciali.

Mansson, A., \& Ahlsen, E. (2001). Grammatical features of aphasia in Swedish. Journal of Neurolinguistics, 14, 365380 .

Marien, P., Abutalebi, J., Engelborghs, S., \& De Deyn, P. P. (2005). Acquired subcortical bilingual aphasia in an early bilingual child: Pathophysiology of pathological language switching and language mixing. Neurocase, 11, 385-398.

Marrero, M.Z., Golden, C. J., \& Espe-Pfeifer, P. (2002). Bilingualism, brain injury, and recovery: Implications for understanding the bilingual and for therapy. Clinical Psychology Review, 22, 463-478.

Marshall, R. S.; Lazar, M. R., \& Mohr,J.P. (1998). Aphasia. Medical Update for Psychiatrists, 3(5), 132-138.

Meinzer, M., Obleser, J., Flaisch, T., Eulitz, C,. \& Rockstroh, B. (2007).Recovery from aphasia as a function of language therapy in an early bilingual patient demonstrated by fMRI. Neuropsychologia, 45(6), 1247-1256. 
Mendez, M. F. (2000). Language-selective anomia in a bilingual patient. Journal of Neuropsychiatry and Clinical Neuroscience, 12(4), 515-516.

Mondini, S., Jarema, G., \& Liguori, F. (2004). Semantics and syntax of mass and count nouns: data from aphasia and dementia. Brain and Language, 91, 138-139.

Munoz, M. L., \& Marquardt, T.P. (2003). Picture naming and identification in bilingual speakers of Spanish and English with and without aphasia. Aphasiology, 17(12), 1115-1132.

Nikolova, R. \& Jarema, G. (2004). The role of morphological structure in the processing of aspectual verb forms in a Bulgarian-speaking aphasic patient. Journal of Neurolinguistics, 17, 349-369.

Nilipour, R., \& Paradis, M. (1995). Breakdown of functional categories in three Farsi-English bilingual aphasic patients. In R.Nilipour, M. Paradis, H. Ashayeri and Sh. Raghibdoust. Syndromes of Aphasia in Persian (Published Research papers) (pp. 121-136).Tehran: State Welfare Organization of Iran University of Welfare and rehabilitation Sciences Press.

Nilipour, R. (2000). Agrammatic language: two cases from Persian. Aphasiology, 14(12), 1205-1242.

Nilipour, R., \& Raghibdoust, S. (2001). Manifestations of Aphasia in Persian. Journal of Neurolinguistics, 14, $209-230$.

Obler, L. K., \& Gjerlow, K. (1999). Language and the brain. Cambridge: Cambridge University Press.

Owens, R. E., Metz, D. E., \& Hass, A. (2000). Introduction to communication disorders: A lifespan perspective. Needham Heights: Allyn and Bacon.

Paradis, M. (1977). Bilingualism and aphasia. In H. Whitaker and H.A. Whitaker (Eds.), Studies in Neurolinguistics, 3 , 65-121. New York: Academic Press.

Paradis, M. (1987). The assessment of bilingual aphasia. Hillsdale, N J, LEA.

Paradis, M. (2000). Generalizable outcomes of bilingual aphasia research. Folia Phoniatrica et Logopaedica, 52(1), 5464.

Paradis, M. (2001a). Bilingual and polyglot aphasia. In R. S. Berndt (ed.). Handbook of neuropsychology, pp. 69-91. Amesterdam: Elsevier Science.

Paradis, M. (2001b). The need for awareness of aphasia symptoms in different languages. Journal of Neurolinguistics, 14, 85-91.

Paradis, M. (2004). A neurolinguistic theory of bilingualism. Amsterdam, The Netherlands: John Benjamins Publishing Company.

Paradis, M. (2008). Bilingualism and neuropsychiatric disorders. Journal of Neurolinguistics, 21, 199-230.

Paradis, M. (2009). Declarative and procedural determinants of second languages. Amsterdam: John Benjamins Publishing Company.

Pena-Casanova, J., Dieguez-Vide, F., Lluent, L. \& Bohm, P. (2001). On Manifestations of Aphasia in Catalan: A Case Study of Broca's Aphasia. Journal of Neurolinguistics, 14, 159-177.

Perani, D. \& Abutalebi, J. (2005). The neural basis of first and second language processing. Cognitive Neuroscience, 15(2), 202-206.

Poncelet, M., Majerus, S., Raman, I., Warginaire, S. \&Weekes, B. S. (2007). Naming actions and objects in bilingual aphasia: A multiple case study. Brain and Language, 103, 238-249.

Postman, W. A. (2003). Working memory disturbances and processing of verbal suffixes: a case study of aphasia in Indonesian. 4th Science of Aphasia Conference, Trieste, Italy.

Roberts, P.M., \& Deslauriers, L. (1999). Picture naming of cognate and non-cognate nouns in bilingual aphasia. Journal of Communication Disorders, 32, 1-23.

Rumiati, R. (2007). Aphasia. Retrieved on $14^{\text {th }}$ June, 2012 from www.sissa.it/cns/scin/publications.html.

Salehnejad, L. (2006). Study of agrammatism in the speech of adult Persian Broca's aphasic speakers. Unpublished M.A. Thesis. Allame Tababaii University: Tehran.

Scarna, A., \& Ellis, A.W. (2002). On the assessment of grammatical gender knowledge in aphasia: The danger of relying on explicit, metalinguistic tasks. Language and Cognitive Processes, 17(2), 185-201.

Sebastian, R., Kiran, E., \& Sandberg, C. (2012). Semantic processing in Spanish-English bilingulas with aphasia. Journal of Neurolinguistics, 25(4), 240-262.

Semenza, C., Girelli, L., Spacal, M., Kobal, J., \& Mesec, A. (2002). Derivation by prefixation in Slovenian: Two aphasia case studies. Brain and Language, 81, 242-249.

Shaw, V.C. (2007). The effects of grammatical class and lexical stress on word retrieval in aging and aphasia. Unpublished Doctoral Dissertation. University of Iowa.

Tanridag, O. (1993). Afazi. Ankara: GATA Basımevi.

Thompson, C. K. (2006). Single subject controlled experiments in aphasia: The science and the state of the science. 
Journal of Communication Disorders, 39, 266-291.

Tsapkini, K., Jarema, G., \& Kehayia, E. (2001). Manifestations of morphological impairments in Greek aphasia: A case study. Journal of Neurolinguistics, 14, 281-296.

Ulatowska, H. K., \& Olness, G. S. (2001). Dialectal variants of verbs in narratives of African Americans with aphasia: Some methodological considerations. Journal of Neurolinguistics, 14, 93-110.

Ulatowska, H. K., Sadowska, M., \& Kodzielawa, D. (2001). A longitudinal study of agrammatism in Polish: A case study. Journal of Neurolinguistics, 14 , 321-336.

Van der Meulen, I. (2004). Syntactic movements and comprehension deficits in Broca's aphasia. Unpublished Doctoral Dissertation. Leiden University: Utrecht.

Vasic, N. (2006). Pronoun comprehension in agrammatic aphasia: The structure and use of linguistic knowledge. Unpublished Doctoral Dissertation. Leiden University: Utrecht.

Verreyt, N., De Letter, M., Hemelsoet, D., Stantens, P., \& Duyck, W. (2013). Cognate effects and executive control in a patient with differential bilingual apahsia. Applied Neuropsychology: Adult, 20(3), 221-230.

Weekes, S.B., Su, F.I., Yin, W., \& Zhang, X. (2007). Oral reading in bilingual aphasia: Evidence from Mongolian and Chinese. Bilingualism: Language and Cognition, 10(2), 201-210.

Yarbay Duman, T., Aygen, G., \& Bastiaanse, R. (2008). The production of Turkish relative clauses in agrammatism: Verb inflection and constituent order. Brain and Language, 105, 149-160. 